IX.

Aus dem Institute zur Erforsehung der Infectionskrankheiten, Universität Bern.

\title{
Versuche über mit Wachs überzogene Seidenfäden.
}

\author{
Von \\ Dr. N. Saltykoff.
}

In folgendem möchte ich einige Versuche mittheilen, die ich auf Anregung des Herrn Prof. Dr. Kocher mit Seidenfäden im obengenannten Berner Institute angestellt habe, die mit Wachs überzogen waren. In der vorantiseptischen Zeit hat man bekanntlich die zur Naht und Ligatur verwendeten Seidenfäden gewächst und glaubte dabei zu beobachten, dass auf diese Weise weniger leicht Infectionen zustande kämen. Den Einfluss dieser Vorbereitung auf das Zustandekommen einer Infection zu studiren schien wichtig und hat umsomehr Interesse, als man neuerdings auch die IIände mit Wachsüberzug zu schützen sucht.

Es wurden hierüber im Ganzen vier Versuche angestellt, von denen jeder mehrmals wiederholt und controllirt wurde. Zunäehst sei die Methode in Kürze skizzirt.

Methodik. Zur Benutzung gelangte Seidenfaden No. 1, 2 und 3 (Dicke), der für chirurgische Nähte gebraucht wird. Die Fäden wurden in geschlossenen Petriselien Schalen im gespannten Dampf, bei $120^{\circ}$, während $! / 2$ Stunde sterilisirt, getrocknet, mit sterilisirtem Wachs überzogen, vermittelst einer sterilisirten Seheere zerschnitten und die Stückchen auf Gelatine- und Agarplatten in Petri'schen Schalen verimpft. Zum Trocknen der Fäden construirte ich mir eine einfache Vorrichtung, indem ich zwischen den zwei parallelen Wänden eines Kistchens Glasstäbe befestigte, die zum Aufhängen der Fäden dienten. Dieser Apparat wurde ebenfalls im Autoclaven sterilisirt und bei Ge. hrauch mit einer Glasglocke bedeckt. Die Sterilisation des zum Ueberziehen der Fäden dienenden echten Bienenwachses geschah in einer gesehlossenen Porzellanschale, während 1 Stunde bei $150^{\circ}$ resp. 
$1 / 2$ Stunde bei $180^{\circ}$ trockener Hitze, oder während 2 Minuten auf dem Sandbade bei $250^{\circ}$. Beim Ueberziehen der Fäden wurde das Wachs vermittelst einer in den Flammen sterilisirten Pincette aus der Porzellanschale entnommen und die Fäden, die zwischen zwei Klemmpincetten 'gestreckt gehalten wurden, damit eingerieben. Für jeden Faden benützte man stets eine frische Wachsportion. Später kam ich dazu, um die Manipulation ähnlich dem Vorgange zu gestalten wie er bei der chirurgischen Praxis gebräuchlich ist, das Wachs in Glasröhren zu sterilisiren, die an einem Ende zugeschmolzen, am andern, offenen Ende mit einem Wattepfropfen versehen waren. Nach vollzogener Sterilisation und Abkühlung des Wachses wurde das zugeschmolzene Ende angefeilt und abgebrochen, durch die Flamme gezogen, das Wachs vermittelst eines sterilisirten Glasstabes um die Hälfte seiner Länge nach aussen vorgeschoben, das Röhrchen wieder durch die Flamme gezogen und das Ganze nun in sterilisirten, geschlossenen Petri'schen Schalen zum Gebrauch aufbewahrt. Das Wachs wurde stets unmittelbar vor dem Gebrauche bereitet. Das weitere Verfahren bestand nun darin, dass man das Rölırchen mit der rechten Hand fasste und den, mit der linken Hand zwischen zwei Klemmpincetten gespannt gehaltenen Faden mit dem Wachscylinder, der aus dem einen Ende des Röhrehens hervorragte, gründlich einrieb. Am Schlusse dieser Procedur wurde der Faden durch die ganze Dicke des Wachscylinders durchgezogen, um die Bedeckung möglichst gleichmässig zu machen. Es sei noch hinzugefügt, dass bei der Einreibung Rücksicht darauf genommen wurde, dass stets neue sterile Strecken des Wachses zur Benutzung gelangten. Für jeden Faden entnahm man stets ein frisches Röhrchen (meistens 3 Stück für jeden Faden) Die Durchtrennung der Fäden geschah, wie schon erwähnt, vermittelst einer Scheere, die nach jedem Schnitt in der Flamme sterilisirt wurde. Die Theile der Fäden, die zwischen den Branchen der Klemmpincette sich befanden, wurden für die Versuche niemals benutzt, sondern stets nur das freie unberührte Mittelstück des Fadens verwendet.

Bei den Culturversuchen wurden die Fadenstïckchen auf die Oberfläche der Nährböden aufgelegt und mit der Oese angedrückt.

1. Versuch. Der erste Versuch diente als Controlle für die Zu. verlässigkeit der Methode. Es wurden Agar- und Gelatineplatten in Petrischalen mit sterilisirten und getrockneten Fäden, gewächsten sowohl wie wachsfreien belegt. Die Nährböden blieben, trotz mehrmaliger Wiederholung dieses Versuches, stets steril. Somit dürften wir unser Verfahren als zweckdienlich betrachten. 
2. Versuch. Schräg-Agarculturen von Prodigiosus, Pyocyaneus, Staphylococcus aureus und sporenhaltigem Milzbrand wurden in steriler Bouillon aufgeschwemmt, die sterilisirten Fäden mit dieser Emulsion durchtränkt und dann auf dem beschriebenen, mit der Glasglocke zug edeckten Apparate zum Trocken aufgehängt. Die Hälfte der inficirten und getrockneten Fäden wurde in der angegebenen Weise (in der ersten Zeit vermittelst einfacher, mit der Pincette gefassten Wachsstückchen, später mit dem in Röhrchen befestigten Wachs) mit einem Wachsüberzug versehen; die andere Hälfte blieb ohne Wachsüberzug. Sämmtliche Fäden, gewächste und ungewächste wurden hierauf auf Gelatine- und Agarplatten verimpft. Dieser zweite Versuch wurde, wie aus der Tab. I ersichtlich, öfters wiederholt. Es fand stets Wachsthum der imprägnirten Bacterienarten statt, sowohl auf Gelatine, wie auf Agar und zwar nicht nur an den Enden der geimpften Fäden, wo vielleicht der Wachsïberzug ein mangelhafter und unvollkommener war, sondern der ganzen Länge des Fadens nach. Nur einmal blieb bei einem mit Staphylococcus aureus imprägnirten und gewächsten Faden das Wachsthum aus, und ein anderes Mal konnte bei einem mit Milzbrand inficirten, gewächsten Faden, gegenüber dem nicht gewächsten Controllfaden, ein verspätetes Wachsthum constatirt werden. Aus diesem Versuch geht also hervor, dass ein Durchwachsen der Bacterien durch den Wachsüberzug hindurch stattfindet.

3. Versuch. Es wurden Fäden mit den angegebenen Bacterienarten imprägnirt und darauf zum Theil mit einem Wachsüberzug versehen und zum Theil ohne einen solchen belassen. Beide Fadenarten wurden sodann während 5 Minuten der Einwirkung einer 1\%0 Sublimat- resp. einer 5\% Cresapollösung ansgesetzt. Hierauf folgte das Trocknen und schliesslich die'Verimpfung der so behandelten Fäden. Als dritte Variation fügten wir noch Fädeu bei, die zuerst inficirt, getrocknet und während 5 Minuten desinficirt worden waren, um nachher mit Wachs überzogen und verimpft zu werden. Zur Controlle dienten inficirte, gewächste und ungewächste Fäden, die ohne desinficirt zu werden verimpft wurden. Das Ergebniss war folgendes: die inficirten, nicht gew ïchsten und desinficirten Fäden blieben stets steril; die inficirten, gewächsten und nachträglich desinficirten Fäden ergaben stets Wachsthum; die inficirten, desinficirten und nachher mit dem Wachsüberzug versehenen Fäden blieben steril. Sämmtliche Controllculturen wuchsen gut.

Dieser Versuch zeigt, dass das Desinficiens durch die Wachsschicht hindurch nicht durchzudringen vermag. 
4. Versuch. Sterilisirte Fäden (wie in allen Culturcontrollen Nr. 1, 2 u. 3) wurden mit einer Bouillonemulsion von sporenhaltigem Milzbrand durchtränkt und getrocknet, ein Theil mit Wachs überzogen, der andere frei belassen. Beide Fadenarten wurden subfascial auf Meerschweinchen verimpft. Bemerkt sei, dass die verimpften Fäden stets von gleicher Länge waren und in der gleichen Weise präparirt

Tabelle I.

\begin{tabular}{|c|c|c|}
\hline 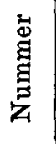 & Versuch & Datum \\
\hline 1 & $\begin{array}{l}\text { Seidenfäden Nr. } 1,2,3 \text { sterilisirt, getrocknet; ein Theil mit Wachs über- } \\
\text { zogen. Wachs sterilisirt } 1 \text { Stunde bei } 150^{\circ} \text { resp. } 1 / 2 \text { Stunde bei } 180^{\circ} \text {, } \\
2 \text { Minuten bei } 250^{\circ} \text { in trockener Hitze (Controlversuche). }\end{array}$ & $\begin{array}{l}\text { 1. Decbr. } \\
\text { 2i. Decbr. }\end{array}$ \\
\hline 2 & $\begin{array}{l}\text { Sterilisirte Seidenfäden (Nr. 3) mit Staphylococeus aureus imprägnirt, } \\
\text { getrocknet, die Hälfte mit Wachs (bis } 150^{\circ}, 180^{\circ} \text { und } 250^{\circ} \text { erhitzt) } \\
\text { überzogen. }\end{array}$ & $\begin{array}{l}\text { 1. Decbr. } \\
\text { 21. Decbr. } \\
\text { 29. Decbr. }\end{array}$ \\
\hline 3 & Dasselbe mit Pyocyaneus imprägnirt (Wachs $150^{\circ}, 180^{\circ}$ ) & $\begin{array}{l}\text { 11. Decbr. } \\
\text { 10. Januar. }\end{array}$ \\
\hline 4 & Dasselbe mit Prodigiosus imprägnirt (Wachs $150^{\circ}, 180^{\circ}, 250^{\circ}$ ). & $\begin{array}{l}\text { 18. Decbr. } \\
\text { 27. Decbr. } \\
\text { 5. Februar. }\end{array}$ \\
\hline$\tilde{\mathbf{s}}$ & Dasselbe mit Milzbrand imprägnirt (Wachs $150^{\circ}$, $180^{\circ}$ ). & $\begin{array}{l}\text { 20. Decbr. } \\
\text { 17. Januar. }\end{array}$ \\
\hline 6 & $\begin{array}{l}\text { Sterilisirte Seidenfäden mit Staphylococcus aureus imprägnirt, hierauf } \\
5 \text { Min. in Sublimat } 1 \% \text { go getrocknet, eine Hälfte mit Wachs überzogen } \\
\text { (Wachs } 150^{\circ}, 180^{\circ} \text { ). }\end{array}$ & 29. Deebr. \\
\hline 7 & $\begin{array}{l}\text { Sterilisirte Seidenfäden mit Staphylococeus imprägnirt, mit Wachs über- } \\
\text { zogen, darauf ă Min. in Sublimatlösung } 1 \% \text { (Wachs } 150^{9} \text { ). }\end{array}$ & 29. Decbr. \\
\hline 8 & Dasselbe wie in Nr. 6 mit Pyocyaneus (Wachs $150^{\circ}, 180^{\circ}$ ). & $\begin{array}{l}\text { 3. Januar. } \\
\text { 10. Januar. }\end{array}$ \\
\hline 9 & Dasselbe wie in Nr. 7 mit Pyocyaneus (Wachs $150^{\circ}$ ), & $\begin{array}{l}\text { 3. Januar. } \\
\text { 10. Januar. }\end{array}$ \\
\hline 10 & Dasselbe wie in Nr. 6 mit Prodigiosus (Wachs $150^{\circ}$ ). & 5. Januar. \\
\hline 11 & Dasselbe wie in Nr. 7 mit Prodigiosus (Wachs $150^{\circ}$ ). & 5. Januar. \\
\hline 12 & Dasselbe wie in Nr. 6 mit Milzbrand (Wachs $150^{\circ}$, Seide Nr. 2). & 17. Januar. \\
\hline 13 & Dasselbe wie in Nr. 7 mit Milzbrand (Wachs $150^{0}$, Seide Nr. 1). & 17. Januar. \\
\hline 14 & $\begin{array}{l}\text { Dasselbe wie in Nr. } 6 \text { mit Prodigiosus, aber anstatt Sublimat } 5 \text { proc. } \\
\text { Cresapol. }\end{array}$ & 18. Januar. \\
\hline 15 & Dasselbe wie in Nr. 7 mit Prodigiosus und Cresapol $5 \%$. & 18. Januar. \\
\hline 16 & Dasselbe wie in Nr. 6 mit Staphylococcus aureus und Cresapol $5 \%$. & 18. Januar. \\
\hline 17 & Dasselbe wie in Nr. 7 mit Staphylococcus aureus und Cresapol $5 \%$. & 18. Januar. \\
\hline
\end{tabular}


wurden. Die Schliessung der Wunde geschah in einem Theil der Versuche vermittelst einer fortlaufenden Naht, in einem andern Theil wurde die Wunde nur mit einem Collodialstreifen geschlossen. Alle Thiere, sowohl diejenigen, die mit gewächsten, wie die, welche mit ungewächsten Fäden geimpft worden waren, starben an Milzbrand; aus dem Blute der gestorbenen Thiere erhielt man stets Reinculturen

Versuche in vitro.

\begin{tabular}{|c|c|c|c|c|c|c|c|c|c|c|c|}
\hline \multicolumn{4}{|c|}{ Mit Wachs } & \multicolumn{4}{|c|}{ Ohne Wachs } & \multicolumn{4}{|c|}{ Controlle } \\
\hline \multicolumn{2}{|c|}{ Agar } & \multicolumn{2}{|c|}{ Gelatine } & \multicolumn{2}{|c|}{ Agar } & \multicolumn{2}{|c|}{ Gelatine } & \multicolumn{2}{|c|}{ Agar } & \multicolumn{2}{|c|}{ Gelatine } \\
\hline $\begin{array}{l}\text { Zahl d. } \\
\text { Platten }\end{array}$ & \begin{tabular}{|l} 
Wachs- \\
thum
\end{tabular} & $\begin{array}{l}\text { Zahl d. } \\
\text { Platten }\end{array}$ & \begin{tabular}{|} 
Wachs- \\
thum
\end{tabular} & $\mid \begin{array}{l}\text { Zahl d. } \\
\text { Platten }\end{array}$ & $\begin{array}{l}\text { Wachs- } \\
\text { thum }\end{array}$ & $\left|\begin{array}{ll}\text { Zahl } & \text { d. } \\
\text { Platten }\end{array}\right|$ & $\begin{array}{l}\text { Wachs- } \\
\text { thum }\end{array}$ & $\begin{array}{l}\text { Zahl d. } \\
\text { Platten }\end{array}$ & $\begin{array}{l}\text { Wachs- } \\
\text { thum }\end{array}$ & $\begin{array}{l}\text { Zahl d. } \\
\text { Platten }\end{array}$ & $\begin{array}{c}\text { Wachs- } \\
\text { thum }\end{array}$ \\
\hline 6 & 0 & 6 & 0 & 6 & 0 & 6 & 0 & - & - & - & - \\
\hline 3 & 0 & 3 & 0 & 3 & 0 & 3 & 0 & - & 一 & - & - \\
\hline 4 & + & 4 & 0 & 4 & + & 4 & + & - & - & - & - \\
\hline 6 & + & 6 & + & 6 & + & 6 & + & - & - & - & - \\
\hline 3 & $\frac{1}{3}$ & 3 & + & 3 & + & 3 & + & - & - & - & - \\
\hline 6 & + & 6 & + & 6 & + & 6 & + & - & - & - & - \\
\hline 2 & + & 2 & + & 2 & + & 2 & + & - & - & - & - \\
\hline 6 & + & 6 & + & 6 & + & 6 & + & - & - & - & - \\
\hline 3 & + & 3 & + & 3 & + & 3 & + & - & 一 & - & - \\
\hline 2 & $t$ & 2 & + & 2 & + & 2 & + & - & - & - & - \\
\hline 4 & +1 & 4 & $+1)$ & 4 & + & 4 & + & - & - & - & 一 \\
\hline 3 & +1 & 3 & + & 3 & + & 3 & + & - & - & - & - \\
\hline 3 & 0 & 3 & 0 & 3 & 0 & 3 & 0 & 2 & + & 2 & + \\
\hline 3 & + & 3 & + & -- & - & - & - & - & - & - & - \\
\hline 3 & 0 & 3 & 0 & 3 & 0 & 3 & 0 & 1 & + & 1 & + \\
\hline 2 & 0 & 2 & 0 & 2 & 0 & 2 & 0 & 1 & + & 1 & + \\
\hline 3 & + & 3 & + & - & - & - & - & - & - & - & - \\
\hline 2 & + & 2 & + & & & & & & & & \\
\hline 3 & 0 & 3 & 0 & 3 & 0 & 3 & 0 & 1 & + & 1 & + \\
\hline 2 & + & 2 & + & - & - & 一 & - & - & - & - & - \\
\hline 2 & 0 & 2 & 0 & 2 & 0 & 2 & 0 & 1 & + & 1 & + \\
\hline 2 & + & 2 & + & - & 一 & - & - & - & - & - & - \\
\hline 2 & 0 & 2 & 0 & 2 & 0 & 2 & 0 & 1 & + & 1 & + \\
\hline 2 & + & 2 & + & - & - & - & - & - & - & - & - \\
\hline 2 & t) & 2 & 0 & 2 & 0 & 2 & 0 & 1 & + & 1 & + \\
\hline 2 & + & 2 & + & - & - & - & - & - & - & - & - \\
\hline
\end{tabular}

1) Wachsthum etwas später als bei Fäden ohne Wachs. 
206 IX. SaLtyKoff, Versuche über mit Wachs tiberzogene Seidenfäden.

TaBelLe II. Versuche in vivo.

\begin{tabular}{|c|c|c|c|c|c|}
\hline ż & Versuch & $\begin{array}{l}\text { Tag der } \\
\text { Impfung }\end{array}$ & Mit Wachs & Ohne Wachs & Bemerkungen \\
\hline 1 & $\begin{array}{l}\text { Vier sterilisirte Seidenfäden } \\
\text { mit Milzbrand imprägnirt, } \\
\text { getrocknet, zwei von ihwen } \\
\text { mit sterilisirtem Wachs über- } \\
\text { zogen, alle vier auf } 4 \text { Meer- } \\
\text { schweinchen subfascial ver- } \\
\text { impft. }\end{array}$ & 1. Febr. & $\begin{array}{c}\text { nicht } \\
\text { gestorben }\end{array}$ & $\begin{array}{c}\dagger 5 . / I I . \\
\text { (Milzbrand) } \\
\\
\\
\text { nicht } \\
\text { gestorben }\end{array}$ & $\begin{array}{c}\text { Bei Section } \\
\text { keine Milz- } \\
\text { brandbacillen } \\
\text { gefunden. }\end{array}$ \\
\hline 2 & $\begin{array}{l}\text { Dasselbe, eine andere, sehr } \\
\text { virulente Milzbrandeultur }\end{array}$ & 27. Febr. & $\left.\begin{array}{l}\dagger \text { 2./III. } \\
+1 . / \mathrm{III} .\end{array}\right\}$ & $\left(\begin{array}{l}\dagger \\
+2 . / \mathrm{III} . \\
\dagger\end{array}\right\}$ 2./III. & - \\
\hline 3 & $\begin{array}{l}\text { Dasselbe, mit derselben } \\
\text { Cultur }\end{array}$ & 3. März & 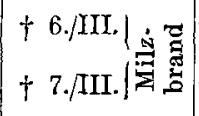 & $\left.\begin{array}{l}\dagger \text { 5./III. } \\
+ \text { 5./III. }\end{array}\right\}$ & - \\
\hline 4 & $\begin{array}{l}\text { Dasselbe, mit derselben } \\
\text { Cultur }\end{array}$ & 7. März & $\left.\begin{array}{c}+9 . / \text { III. } \\
+10 . / \text { III. }\end{array}\right\}$ & 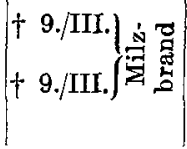 & $\begin{array}{l}\text { Eine Stunde } \\
\text { später als die } \\
\text { andern beiden } \\
\text { ohne Wachs. }\end{array}$ \\
\hline
\end{tabular}

von Milzbrand, welcher Umstand ebenfalls für die Zuverlässigkeit unseres Verfahrens spricht. Nur in 2 Fällen trat der Tod bei den Thieren, die mit gewächsten Fäden geimpft worden waren, 1 resp. 2 Tage später ein, als bei den Controllthieren. Auch dieser Versuch lebrt also, dass der Durchgang von Bacterien durch die Wachsschicht nicht behindert wird.

Schlusssätze. 1. Bacterien an der Oberfläche von Seidenfäden dringen durch eine Wachsschicht dureh.

2. Desinficientien dringen durch eine Wachsschicht nicht durch.

Folgerung: Die Anwendung von gewächsten Fäden bei der Wundnaht hat keine Vortheile (Durehlässigkeit für Bacterien) und bringt eventuell Nachtheile (Undurchlässigkeit für Desinficientien).

Am Schlusse sei es mir gestattet, Herrn Prof. Dr. Tavel, Director des Institutes, für seine liebenswürdige Hilfe und Anleitung bei dieser Arbeit meinen besten Dank auszusprechen. 